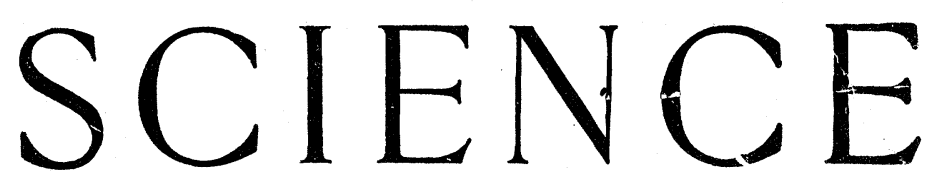

NEW YORK, JULY 1, 1892.

\section{NATURAL SCIENCE IN THE HIGH SCHOOL COURSE.}

BY R. ELLSWORTH CALL.

THERE is needed no argument to demonstrate the necessity of training in science. It will be assumed that such training is recognized as essential, and that its attainment can in no manner now be dropped from the curricula of the high schools. It is proposed, therefore, to briefly discuss the theme under (1) Comparative Educational Value, (2) Practical Character of the Information Gained, (3) The Tendencies of the Culture of the Day, and (4) Relations to University Requirements.

\section{Comparative Educational Value.}

It appears to be a difficult matter to discuss this feature of the proposed theme without the bias that comes either from one's own training or one's taste. Something must be conceded from either standpoint; but concession is difficult and especially so when demanded on the basis of culture value. Rather, then, than on individual opinion must estimation of comparative value be based on culture results. But what constitutes culture? Is it ability to master in ordinary array numerous facts, devise and defend delightful theories, display extended and intimate acquaintance with art, history, or song? Is it held to consist in deep research into lifeless tongues, effete philosophies, degenerate religions? Shall it rest in useful citizenship, productive thought, inventive genius, polished rhetoric, political leadership? These one and all enter into the various conceptions of culture, and these all demand a hearing. Shall they be heard? And how?

I take it that the prime factor in any educational system lies in its power to discipline. The numerous facts which the young person gains during the brief period of four years in the best high schools represent but a very small portion of the sum that marks human attainment. Not the facts, nor their class alone, give the chief feature that is valuable in school life. The collation of facts from observation, their orderly and systematic arrangement, their intelligent discussion, their applicability to the circumstances of the individual by way of amelioration, their power to draw out and direct the best side of the mind, this is discipline. But is not this also applied science? Of such discipline the self is the end. It is not culture for a vocation, for professional training, nor is it culture for an end. It is discipline as a means.

It will be conceded, I presume, that all kinds of culture have not an equally important bearing on every line of activity in life; there is, or should be, occasion for discrimination and choice. Culture, or, if one please, discipline, ought to conform to this natural principle of selection. As a matter of fact and of experience it is found that a student usually. accomplishes but little till a definite and settled purpose presides over his movements, or over his intellectual tendencies. The energies of youth are limited, naturally. To save from waste time, which has to a young man quite as much value as effort, practical definiteness should be given to scholastic education. To this end, I believe, that selection of those practical or professional activities, which alone have been deemed most effective in conserving, importing, and transmitting the civilization of any age, should be singled out for school work. In this elective sense, and in this sense alone, every age has taught what it knew and taught all it knew. In former days the physical sciences were not taught because they were not known; they are taught now because they are known. A proper interpretation of the historic facts, therefore, assigns to the physical sciences, in their phenomenal and empirical aspects, a place in the foreground.

As a means of purely mental training I am disposed to accord the first place to physical science. There is involved more than a suggestion of mathematics, more than mere ability to frame correct sentences, more than memoriter exercises respecting isolated facts. Physical science means, if it mean aught, extended application of mathematical data and methods, statement of facts in other than sentential relations, the discovery - whether for the first time it matters not- of underlying laws. This is culture of the very broadest nature; this means ability to generalize; this constitutes the first stage in a successful intellectual career. I do not believe that one who is abundantly able to develop Sturm's Theorem, trace all the wanderings of the heroes of the Odyssey or the Aneid, outline the journeys of Paul in Asia Minor, or discover meanings in the "Taming of the Shrew," of which its great author never dreamed, can compete in intellectual vigor with the lad able to determine the constitution of a compound substance, decide correctly the affinities of a noxious, stranger plant, or to read facts older than the pyramid of Cheops in a scratched pebble found at the schoolhouse door. The one reads fictions long bereft of true educational value; the other deals with the facts of our daily lives. The one lives and thinks with an ancient, stranger people; the other breathes an atmosphere of intellectual activity and intellectual endeavor. The one deals with symbols - with words as various in significance as are different the minds that use them; the other with laws, unchanging, necessary, logical. The one taught by novelists, dramatists, and poets whose function it is to create imaginary worlds, dwells in an ideal world constructed to suit himself; the other lives in the midst of things of practical accomplishment. It seems to me, therefore, that this difference in the mental aptitudes of students trained side by side, one trained in science, the other in a literature in which even the masterpieces of scientific writing find no place, will stand equally well for the probable values of their influence in after years in determining the current of events,

I would have, then, a still more extended pursuit of physical science in the high school. By this it is not meant that the additional work be in the line of new subjects, but that the time now devoted to belles lettres and ancient languages be curtailed; that the time thus gained be given, not to new subjects, but to the more extended prosecution of the few. The point sought to be enforced is that two or three subjects in science, involving observation, technic, and reflection, as botany or physics, zoology or chemistry, be prosecuted for 
very much longer periods. The business of the high school is to train, to develop, to direct, not to give encyclopædic information nor to render the student an intellectual automaton. Its great aim is to awaken thought, not as an end but as a means. Divorce such awakening from the rhetoric of pure philosophy, from the generalities of literature, from the dicta of questionable schemes. Join it to the exact methods involved in scientific research - whether original or in the lines laid down by another matters little; wed it to demonstration of natural law - whether before known is unimportant; weld it indissolubly to those mental processes which involve the most intelligent ratiocination, and the high school curriculum has attained its maximum educational value. But this assumes increased attention to and prosecution of pure science, and in this, we believe, lies the best and greatest educational power.

Practical Character of the Information Gained.

Ten years ago, the English physicist, Professor Sylvanus P. Thompson, wrote the following: "And ought we, then, to be surprised if, in pursuance of the system we have deliberately marked out for the rising generation, we keep our future artisans, till they are fifteen or sixteen, employed at no other work than sitting at a desk to follow, pen in hand, the literary course of studies of our educational code, we discover that, on arriving at that age, they have lost the taste for manual work, and prefer to starve on a threadbare pittance as clerks or bookkeepers rather than gain a livelihood by the less exacting and more remunerative labor of their hands?" True it is that this remark was volunteered in defense of a proposed scheme for technical trainıng-a scheme, the necessity of which is self-evident even in this country, as is witnessed by the establishment of numerous manual training schools. But this does not dull its edge nor blunt its point. The ordinary training in the high school is not suited to the demands of practical living.

It is idle, perhaps, to volunteer the remark that this is a wonderfully practical age and this great West a model of practical life. The conditions that make the environment here are not met by the ordinary scholasticism of the mother East. We can scarce do less, then, than recognize that the high school stands as the expression of the educational needs of a community. Those needs are limited or determined by the multitudinous business interests involved, and, though these be legion, sound economic theory and sound educational science alike demand their recognition in the various schemes of study. Such recognition has not always been accorded, and the small percentage of high school graduates stands somewhat in the attitude of menace to their perpetuity.

The boy or girl who is skilled in the necessary technic of the physical or chemical laboratory has become a most useful member of the community. There are no secrets that are unsearchable, no mysteries intangible, no hopeless intellectual dabbling possible in the laboratory. Principles, system, painstaking manipulation rule therein, and they are necessary. To the one versed only in the arts of literature, the relations and significance of coulombs and atomic weights, of farads and valence, of amperes and reagents, are neither attractive nor necessary. 'But, if disciplinary value alone be sought, who shall say that intellectual training may not come as truly to bim who intelligently uses a galvanometer or a burette as to him who traces his mother-tongue to its ancient stock? And if both are to be measured by manual skill, by ability to devise and to execute, to draught and to realize, who shall say that the student inducted into that truer field of investigation and deduction, implied in the proper pursuit of physical science, has not an immeasurable advantage? He has, at command, a literature limited only by the bounds imposed upon physical research, methods as variant as the students who have trod the paths before him are different, opportunities for usefulness co-extensive with the physical needs or comforts of the highest civilization.

It seems to us that the time given to physical science in the ordinary high school curriculum is far too short to reach the highest practical advantages Usually such curricula encompass the whole round of scientific endeavor. A few weeks to this, somebody's "fourteen weeks" to that, and a term to a third subject - these of ten without logical sequence - and the boy or girl goes forth trained in science. Did I say trained? Forsooth, the first principles have not been mastered, the technic is entirely unknown. Add to this the positive, and, it will be granted, unfortunate fact that science subjects are taught by persons themselves untaught in either the matter or spirit of science, still less the method, and the cause of comparative failure is at hand. We say comparative failure, and use the term advisedly. We use it, because never less than a year is devoted to algebra, often more, usually an equal period to geometry, and the lion's share of the time is given to language work. All the disciplinary power possible is thus given to these subjects, and those who teach them recognize that time, and time alone, is productive of fruitful results. One, who in the face of such educational fadism, would dare suggest two years of botany or of zoology, three or four years of chemistry or of physi s, would surely, like Paul, be thought "beside himself." And yet this is exactly the position we seek to defend. It will be conceded, we imagine, that science has disciplinary value, that its prosecution develops a most desirable phase of mental life, that in its exacting and painstaking methods it stands without a peer; it will also be granted that among those who have traversed its inviting fields, thought and written on what they have seen and felt, there are very many who have enriched, immeasurably, the literature of their several lands; in short, it must be granted, it seems to us, that no phase of human thought exists which can be valuable for training in the high school that does not find an equally valuable counterpart in the sphere of science. The multitude of ways in which such knowledge and training may enter into every-day life, in every social condition, renders the argument of practical utility unanswera ble.

The radical feature in science training lies in the assumption that even elementary education should "supply that exact and solid study of some portion of inductive knowledge," which Dr. Whewell long ago pointed out as a want in educational method. Through it education "escapes from the thralldom and illusion which reign in the world of mere words." The student's own examination and investigation of phenomena, his own conception of their relations and values, his own inferences concerning the laws he supposes to underlie the surface of things, these all constitute the practical side of his education. In this sense, it seems to us, physical science possesses a paramount value, and should be placed accordingly in a wisely adjusted scheme for study.

The Tendencies of the Culture of the Day.

Educational systems and schemes reflect, it will be conceded, the culture tendencies prevalent during their inaugural. It cannot, however, be assumed that their arrangement has always been best, or that it has always fallen into the wisest and safest hands. The fault 
lies, not in the system, perhaps, which may be good enough considered as an end, but in the personal training of those who have had these systems in charge. I think it true that educational methods and dicta are among the very last, if we except theology, to yield to the demands imposed by changing environ ment. To one cultured along the lines fashionable a decade ago, it becomes a difficult task to change methods and opinions that are the outgrowth of such discipline. The maintenance of courses of study that are either largely classical or mathematical means simply a system based upon methods in vogue long since. A compromise is noted, however, in those schools in which a so-called "scientific course" is provided; from this concessisn it is easy to pass to those schools whose work is largely along the lines imposed by physical science.

This modification - whether it be forced or natural is immaterial - reflects the tendencies of the thought of the day. On all sides, and in all manner of ways, increased attention is being given to physical science. The reason is not past finding out - it lies close at hand. Science enters into the home, social and mercantile life of the world to a degree never before known in the history of mind. It has builded upon a foundation broadly and well laid, because laid primarily with a just appreciation of the physical necessities of man. Those who now toil, and no longer with unrequited labor, in the laboratories of the world have felt and still feel the impetus due to the appreciation. Not a law of life, not a condition in the physical environment of men, not a pest that may destroy his stores or his comfort, not a product of land, sea or air, but somewhere some one is busy working out details, deducing laws, formulating results, suggesting utilities. The world is en rapport with works of this sort, and it is by no means uninformed as to their value. A new law of light, a new application of electric force, a new fact in chemistry, a new method of locomolion, these all are heralded as to an expectant community. The world waits for facts such us these, the world expects them.

The question turns now on the manner in, and the extent to which this tendency is to be recognized in the high school curriculum. It does not need a prophet's vision, nor a sage's wisdom to give the answer. It will be answered on the lines that have reference to the circumstances, duties, and work of life. It were idle to stem the tide even were it desirable. It is not a counter-argument that the term "practical tendency" is accepted at its narrowest meaningthat of bare and specific preparation for professional or business pursuits. But if even such illogical answers should be made, the fact still remains that the high school is the poor man's college. It furnishes the highest education which the major portion of the young men and women of a community can obtain. Who, then, shall say that it should not prepare, not alone for right living, which is solely a subordinate and moral aspect of the question, but for successful business living? Why should not the studies pursued have discipline as a means and utility as an end We do not believe a thoughtful, intelligent answer can be negative. We ask, then, a modification of the traditional curriculum and the institution - better perhaps to say substitution - of one which has as a prominent feature the culture of today. The time has passed when one ignorant of the laws of health and the gross anatomy of the person, ignorant of the chemistry of cookery and the laws of ventillation, ignorant of the dynamics of physical nature and unlearned as well as unskilled in the manipulations of the laboratory, may pose as a cultured man, though his knowledge of wonderful tongues and skill in rhetorical or literary art be never so great. "What can you do ?" not "what do you know?" is the question of the hour, and the high school of to-day and of the future will be compelled to answer the question. Will it do it completely? Not as at present constituted, nor, if like the barrister, it be bound by the law of precedents, will it ever intelligently answer it.

\section{Relation to University Requirements.}

To this phase of the subject attention will be but briefly directed. The high school does not exist for the college or the university; it is an end in itself. Its original institution did not contemplate its relations to these institutions as a gymnasium, but appears to have resulted from the more universal methods of gradation of school work. In cities it was learned that the time required to master the elementary studies could be much shortened by rigid system and rigid enforcement of its necessary provisions. Following this it was discovered that students might complete their school life at too early an age. Additional studies were introduced, and finally a system involving a secondary education, formerly confined to private academies and seminaries, became a part of the public school scheme; the high school became a fact.

There can be no question that popular education did not contemplate the establishment of the high school. To many, and to us, its legal right to exist is questionable. However that may be, the high school has come to stay. It has the support and sympathy of the liberally educated classes, and is not unappreciated by the less fortunate grades in society. So that the problem of its curriculum must be worked out in view of the interest these two classes of society evidence in general education.

At the end of the scheme of public instruction stands the university. Most, if not all, of the States recognize this relationship, and the curriculum of the secondary or high school is derised to conform to it. We think wisely. Recently, in this city, DesMoines, a convention of schoolmasters discussed this, or a nearly related matter, and the opinion at that time expressed evidenced a condition of belief far from unanimity as to the requirements presented by the university authorities. But the university is right in high requirements; right in insisting that secondary instruction be confined to secondary schools; right in assuming that its educational forces are to be exerted along the highest possible lines. Particularly is this true of the requirements in physical science. The proper prosecution of original research, which is certainly a university prerogative, the best presentment of modern scientific thought and method, which is the aim of university education, cannot be realized when its instructors are burdened with quasi-elementary work. So, back upon the high school must fall the work of elementary instruction in physical science. This the university demands, and this the high school must do. Now, in the appointment of the various courses leading to degrees in the universities, it is noticeable, if decade he compared with decade, that more and more are scientific subjects occupying the fore-ground. More time to science, fewer subjects; more stringent requirements, greater opportunity for elections, these are the rule in the modern university and these must be understood and appreciated on the part of the high school. There are few good colleges and no universities of standing which do not now demand at least a year in physics and a year of botany. In most others biological subjects are held as essential, and not a few require a fairly 
complete cours̀ in physical geography - of all high school subjects the most difficult and the one most commonly poorly taught. Certain universities, as Harvard and Michigan, require elementary chemistry; others entirely omit it, because in it students are too often poorly prepared. Said a university professor of chemistry to me, not long ago, "I prefer my students to come to me with no chemistry. I find they too often come with matter and methods to be unlearned." Now, this must be remedied in the chemistry work of the high school; the "indictment must be quashed ;" the fault must be corrected by proper instructions and skilled methods. Without appliances, that is to say, without laboratory facilities, radical and valuable revolution is impossible. Physical science in the high school must be experimental.

Without multiplying words, then, it may be stated that the high school must give, to those who ask it, preparation for entrance into university work. It must adapt its science curriculum to the requirements of the standard college or university. For long years these higher institutions compelled certain and definite work in language and mathematics, they compel that work, witl little or no modification to-day. Why cannot they, equally well, compel proper science preparation? We believe they can; we think they will.

There will not be, in the nature of things there cannot be, a set limit to science requirements in the universities. As the tables of the various laboratories, physical, chemical, physiological and biological, become over-taxed, up go the requirements. The standards of entrance are being steadily raised, especially in Indiana University, Michigan University, Cornell, Yale, Harvard, and Leland Stanford, Jr., Universities, as fast as the high and other secondary schools will admit of it. So there is no goal; no end; the high school will ever need to keep close watch on university matters and determine its own work accordingly. Our own State university proposes to the high school to occupy advanced ground in this very matter; to gain and hold the confidence of the university, on the one hand, to meet a legitimate demand for more complete preparation in science on the other, the high school course must be materially modified.

\section{THE FEEDING OF HORSES.}

Bulletin No. 13 of the Agricultural Experiment Station of Utah has been received. This bulletin reports the results of a feeding trial of horses by the director, J. W. Sanborn. It reports the result of a trial in a direction that the American Experiment Station literature is almost silent upon, viz., feeding horses hay and grain mixed, and feeding cut against whole hay to horses.

It is a common belief with horsemen that when grain, especially meal, and more especially such meal as corn meal, is fed to horses alone or mixed with hay, it tends to compact in the stomach and produce indigestion. It is believed that it so far compacts that the gastric juices do not have free access to the mass of it. Furthermore, it is believed to be subject more to the washing influence of heavy drinking. In the latter respect it is known that the horse's stomach is very small, and that grain is liable to be washed out of it, as the stomach necessarily overflows with water.

As usual, the writer fed two lots of horses for nearly three months, one lot with hay and grain mixed, and the other lot with hay and grain fed separately. At the end of this period the food was reversed, and the horses were fed some two months more. It would be unnecessary to quote the figures of lengthy trial. Suffice it to say that it was found that horses, as in the case of cattle and pigs, showed no disadvantage by the division of the grain and hay into separate feeds over feeding hay mixed with grain. Indeed, in this trial he found a disadvantage for the horses on the hay and grain mixed, they not maintaining their weight as well. The author ascribed this result to the fact that the timothy hay when cut fine, with its sharp solid ends, irritated and made sore the mouths of the horses, and possibly induced too rapid eating, as when the hay and grain were moist they would be more likely to eat more rapidly than when fed dry. As this trial is in accord with trials with ruminants and with the pig, it would seem quite probable that the old and persistent argument in favor of mixing hay and grain is not sound.

The second trial reported in this bulletin covered feeding of cut against whole hay to horses. This trial also covered two periods in which the foods were reversed with the sets, in order to determine whether any change of weights found was due to the individualism of the horses, or whether it was due to the system of feeding. The two periods covered from August 10 to December 31. As in the other case, we will not review the tabulated data that accompany the bulletin. This trial was very decisively in favor of the cut clover for the four months and a half covered by this period. The food fed was clover, and the author points out the fact that clover hay and lucerne, unlike timothy hay, do not present sharp, solid, cutting edges. The results are decisive, and in accordance with those of a trial made by the Indiana Experiment Station with cattle. Director Sanborn points out the fact that these trials, covering nearly a year's time with four horses, showed that horses consume practically the same amount of food that cattle do when high fed, and make it somewhat clear that horses make as economical use of hay and grain as do cattle, and he calls attention to the fact that the practice of charging more for pasturage of horses, where grooming is not involved, is not well founded. He also shows that less food was eaten during the hot months than during the cooler months, and particularly that the horses ate less grain during the hot months than during the cooler months. The trial seems to show also that a rather large ration of grain for work-horses is an economical one.

\section{NOTES AND NEWS.}

THE idea of flower-farming for perfumes seems to be exciting a good deal of interest in New South Wales, as many inquiries on the subject have lately been submitted to the Agricultural Department. There are at present in the colony no means of illustrating the practical operations of this industry, but the Agricultural Gazette of New South Wales hopes that this deficiency will soon be supplied by the institution of experimental plots on one or more of the experimental farms. The Gazette points out that in scent farms large quantities of waste material from nurseries, gardens, orchards, and ordinary farms might be profitably utilized, while occupation would be found for some who are unfit for hard, manual labor. A Government perfume farm was lately established at Dunolly, in Victoria, and this promises to be remarkably successful.

- At the meeting of the Field Naturalists' Club of Victoria on March 14, as we learn from Nature, Professor Baldwin Spencer, the president, gave an interesting account of a trip he had made to Queensland in search of Ceratodus. Special interest attacbes to this form, since it is the Australian representative of a small group of animals (the Dipnoi) which is intermediate between the fishes and the amphibia. Ceratodus has its home in the Mary and Burnett Rirers in Queensland, whilst its ally, Lepidosiren, is found in the Amazon. and another relative, Protopterus, flourishes 